\title{
The Impact of Economic And National Identity Loss Messages, And The Moderating Effect of Political Orientation, On Climate Change Policy Support
}

Anna Klas ( $\sim$ anna.klas@deakin.edu.au )

Deakin University https://orcid.org/0000-0002-6590-5164

Edward J.R. Clarke

Philipps-Universität Marburg

Kelly Fielding

University of Queensland

Matthew Mackay

Deakin University

Susanne Lohmann

Deakin University

Mathew Ling

Deakin University

\section{Research Article}

Keywords: Mitigation policy, Adaptation policy, Climate change communication, Economic Loss, National Identity Loss, Political Orientation

Posted Date: January 12th, 2022

DOI: https://doi.org/10.21203/rs.3.rs-1172473/v1

License: (9) This work is licensed under a Creative Commons Attribution 4.0 International License.

Read Full License 
1 The Impact of Economic and National Identity Loss Messages, and the Moderating Effect of 


\section{Abstract}

As climate change continues to be politically divisive, developing communications that align with right-leaning beliefs may increase bipartisan support for climate policy. In two experimental studies (Study 1, Australia, $N=558$; Study 2, United States, $N=859$ ), we tested whether an economic loss or national identity loss message would elicit greater support for mitigation and adaptation policies when compared to one another and to a control message. We also tested whether the direct effects of these message types were conditional on political orientation (specifically, identifying as politically right-leaning). In both studies, preliminary analyses indicated that the message manipulations were effective and that there was a high level of support for both types of climate policy. When compared to left-wing adherents, those who were politically right-leaning were less likely to support mitigation and adaptation policies in either sample. Australian (Study 1) identification - although not American identity (Study 2) also uniquely predicted adaptation support (but not mitigation support). Yet, there were no significant message frame or interaction effects in the Australian (Study 1) or U.S. sample (Study 2). This suggests that neither an economic loss nor national identity loss message frame may be effective in overcoming the political polarization of climate change in Australia or the United States. Nevertheless, national identity could still play a useful role in Australian climate communications given its positive relationship to adaptation policy support, and therefore warrants further investigation.

\section{Economic Loss; National Identity Loss; Political Orientation}


CHANGE POLICY SUPPORT

The Impact of Economic Loss and National Identity Loss Messages, and the Moderating Effect of Political Orientation, on Climate Change Policy Support

Anthropogenic climate change requires urgent and effective governmental policy to be implemented (Clayton et al., 2015). One class of needed policies are mitigation-based, wherein the focus is on limiting the severity of climate change through reducing carbon emissions (herein referred to as mitigation policy) (Bateman \& O'Connor, 2016). There is also a need for policies that work to adapt to the inevitable effects of climate change, primarily via infrastructure or technology (herein referred to as adaptation policy) (Bateman \& O’Connor). One strategy to help increase the likelihood of the implementation of these climate policies is to increase the chances of bilateral co-operation and agreement between right- and left-leaning political parties and, by extension, their supporters (Fielding et al., 2020).

Past research has focused on developing informational interventions to increase climate change policy support (Steg \& Vlek, 2009; Nisbet, 2009). However, climate change continues to be politically polarized in nations such as Australia and the United States (Hornsey, Harris, \& Fielding, 2018; Smith \& Mayer, 2019). Right right-wing adherents are less likely to support climate change policy - especially mitigation policy - when compared to their left-wing counterparts in these nations (Dunlap, McCright \& Yarosh, 2016; Fielding, Head, Laffan, Western \& Hoegh-Guldberg, 2012; Hart \& Nisbet, 2012). This politicization of climate change contributes to the effectiveness of climate change communication in Australia and the United States, and therefore future climate action, as individuals often fail to respond well to climate messages that are misaligned with their underlying political beliefs and valued identities (Wolsko, Ariceaga \& Seiden, 2016). 


\section{CHANGE POLICY SUPPORT}

Given these considerations, there is a need to identify message frames that are effective in increasing support for climate policy, especially in those who are politically right-leaning in

51 Australia and the United States (Klas \& Clarke, 2020). As right-wing adherents appear to be

52 sensitive to loss and threat (Feygina, Jost, \& Goldsmith, 2010; Jost, Glaser, Kruglanski, \&

53 Sulloway, 2003), one approach is to develop messages that are loss-oriented and align with their

54 political beliefs and values, such as a preference for economic stability and nationalism. As such,

55 we suggest that there is a need investigate the effectiveness of economic and national identity

56 loss messages on increasing climate policy support in right-wing adherents. Using both

57 Australian (Study 1) and US (Study 2) samples, we investigated whether an economic loss frame

58 that highlighted the potential for climate change to threaten economic stability (by describing

59 how climate change will result in a loss of economic prosperity), or a national identity loss frame

60 that threatened national identity (by describing beloved national environmental locations that are

61 threatened by climate change), could increase support for mitigation and adaptation policies

62 when compared to a control message. We also investigated whether the effects of these messages

63 were conditional on political orientation (specifically, identifying as politically right-leaning).

\section{Political Orientation and Climate Change Communication}

Political orientation often predicts climate change outcomes, especially in Anglosphere

66 nations (Hornsey et al., 2018; Smith \& Mayer, 2019). In Australia and the United States

67 specifically those who are politically right-leaning (or socially/economically conservative) are

68 less likely to believe climate change is happening or is anthropogenic and are less likely to

69 engage in climate action when compared to their politically left-leaning (or

70 socially/economically liberal) counterparts (Dunlap et al., 2016; Leviston \& Walker, 2012).

71 Likewise, right-wing adherents are also less likely support climate change policies, especially 
72 mitigation policies which are focused on limiting the severity of climate change through

73 reducing carbon emissions (e.g., emissions trading schemes or a carbon tax) (Unsworth \&

74 Fielding, 2014).

75 These differences between politically right- and left-leaning individuals when it comes to

76 climate change appear to partially arise due to their underlying political beliefs (Fielding et al.,

77 2020). While right-wing adherents tend to value tradition, nationalism, stability and free-market

78 economic growth, their left-wing counterparts tend to value benevolence, equal opportunity, and

79 environmental protection (Koleva, Graham, Iyver, Ditto, \& Haidt, 2012; Osborne, Milojev \&

80 Sibley, 2017). Further still, even though right-wing and left-wing adherents have similar

81 physiological responses to threat, it is likely that each group is more loss-averse when

82 encountering situations which threaten what their group specifically values (Bakker et al., 2020).

83 For instance, right-wing adherents are sensitive to threats to free-market economic growth or

84 nationalism (an economic and cultural value respectively). Consequently, right-wing adherents

85 are often motivated to maintain current national social norms, preserve the status quo, and/or

86 minimize social or economic change (Feygina, Jost, \& Goldsmith, 2010; Jost, Glaser,

87 Kruglanski, \& Sulloway, 2003).

88 Unsurprisingly then, right-wing adherents appear to be less likely to accept climate

89 change policies if they perceive them to be a threat to the socio-economic status quo, especially

90 if these policies proactively change the current system (Clarke, Ling, Kothe, Klas, \& Richardson,

91 2019). This also suggests that right-wing adherents are less likely to support climate change

92 policy as they are motivated to reduce as much potential 'loss' as possible, especially when this

93 loss is tied to things which they value economically (e.g., economic stability) or culturally (e.g.,

94 nationalism). Yet, one way to reduce this politically polarized response to climate change is to 
95 develop 'message frames' that lessen the intensity of these ideological barriers (Klas \& Clarke, 96 2020).

Message framing typically involves organizing information to emphasize a specific

98 aspect of the issue, without changing the message's overarching viewpoints. One important type

99 of framing in climate change emphasizes gains (rewards) or losses (threats) of taking climate

100 change action (Nisbet, 2009). Climate change gain messages typically present a potential

101 positive outcome that may arise from a proposed action for climate change (e.g., "doing

102 something about climate change will improve health outcomes"), while climate change loss

103 messages usually present the negative outcomes that will arise from failing to act (e.g., "doing

104 nothing about climate change will lead to worse public health outcomes"). Most message frames

105 have produced mixed findings for those who are politically-right leaning (Chinn \& Hart, 2021;

106 Severson \& Coleman, 2015; Singh \& Swanson, 2017; Wolsko, et al., 2016). However, framing

107 messages to align with right-leaning individuals' political beliefs, and thus ensuring they also

108 emphasize the losses that climate change will result in, could be an effective strategy to build

109 bipartisan support for climate change policies. This could especially be the case if the potential

110 losses noted in the message threaten things which right-wing adherents' either economically or

111 culturally value, such as economic stability and nationalism.

112 Aligning with Conservative Economic and Cultural Values: The Potential of Economic and

\section{National Identity Loss Message Frames}

114 Currently, most climate change message frames are either gain focused and/or emphasize

115 content which politically right-leaning individuals' value less (Hart \& Nisbet, 2012; Singh \&

116 Swanson, 2017). For instance, environmental preservation messages are often framed in

117 ideological and moral terms which are more appealing to left-wing adherents as they emphasize 
CHANGE POLICY SUPPORT

118 ecological diversity and community resilience (Bain et al., 2016). Even when message content

119 aligns with right-wing adherents' values, such as their preference for economic stability and free-

120 market opportunities, these economic messages are usually growth or 'gain' oriented (Hennes,

121 Ruisch, Feygina, Monteiro \& Jost, 2016). Yet, emerging research suggests that economic growth

122 messages may be outperformed by economic loss messages, which instead specify the

123 destabilizing global economic impact of environmental disasters (Bertolotti \& Catellani, 2021;

124 Severson \& Coleman, 2015). For instance, seeing messages which promoted climate policy

125 through stressing the negative consequences of not implementing said policies (rather than its

126 positive consequences of implementation) appeared to increase agreement with subsequent

127 economic loss messages (vs gain messages) (Bertolotti \& Catellani, 2021). Further still, while

128 examining climate believers specifically, recent studies in the U.S. and Italy have demonstrated

129 that messages which outlined the potential economic losses of adopting certain policies were

130 more effective in increasing climate policy support when compared to economic gain messages

131 (Bertolotti et al., 2021).

132 Beyond the potential usefulness of an economic loss frame, an alternative and

133 underexplored frame that may also prove fruitful in this context is that of national identity loss.

134 That is, highlighting how climate change may result in losing environmental icons which are

135 valued by an individual's nation and therefore important to a nation's identity. Many

136 Anglosphere nations, such as Australia, view specific environmental icons like national parks

137 and beaches as crucial to their national identity and therefore something that should be protected

138 for the good of the country (Bonaiuto, Breakwell, \& Cano, 1996; Purdie \& Wilss, 2007).

139 Nationalistic attitudes are often also positively correlated with right-wing identification (Osborne

140 et al., 2017), while right-affiliated attitudes positively correlate with one's sense of national 
CHANGE POLICY SUPPORT

141 identification, including right-wing authoritarianism (RWA) and social dominance orientation

142 (SDO) (as seen in the United States; Roccas et al., 2010). This loyalty and gratitude to one's

143 country is often expressed by promoting the interests of one's nation over and above the interests

144 of those external to it. It even appears to occur in environmental contexts with those who are

145 politically right-leaning more likely to be motivated to protect the environment if it means that it

146 will also protect national interests (Sapiains, Beeton, \& Walker, 2016; McCright \& Dunlap,

147 2014).

148 As well as aligning with conservative values, a national identity loss frame taps into

149 conservatives' higher sensitivity to loss when something they value culturally is under threat

150 (Feygina et al., 2010; Jost et al., 2003). For instance, in one study, Feygina et al. (2010)

151 investigated a national identity loss frame with a U.S. sample and found that by presenting pro-

152 environmental messages as patriotic and environmental conservation as key to protecting and

153 preserving the "American way of life", it was possible to increase conservatives support for

154 general pro-environmental behaviours, such as recycling. Similarly, Wolsko et al. (2016)

155 demonstrated right-wing adherents in the U.S. are more likely to support climate change action

156 when exposed to a frame that outlined how protecting the natural environment is a matter of

157 obeying authority, defending the purity of nature, and patriotism (all conservative values).

158 Finally, research with Australians who rejected anthropogenic climate change showed that they

159 were more likely to support climate change policies after receiving a national identity gain

160 message when compared to biodiversity or economic gain messages (Sapiains et al., 2016).

161 While none of these findings examined a national identity loss frame, its comparison to

162 economic loss message specifically, and whether its effectiveness was conditional on political 
163 orientation, they do point to the potential usefulness of developing message frames that target

164 conservative values of economic stability and nationalism for right-wing adherents.

\section{The Present Research}

166 The aims of this research were to investigate whether an economic loss or national

167 identity loss message increased climate change policy support when compared to one another

168 and to a control message, and whether their potential effectiveness was conditional on political

169 orientation (specifically, right-wing political orientation). We conducted two online experimental

170 studies to test these aims: the first in Australia (Study 1) and the second in the United States

171 (Study 2). Australia presents a ripe area to test these potential effects as the topic of climate

172 change continues to be politically polarizing and the country itself rates as one of the lowest

173 performing Western nations on climate policy (Sachs et al., 2021). Furthermore, Australia relies

174 heavily on fossil fuel exports for its Gross Domestic Product (GDP) (Department of the

175 Environment and Energy, 2018), even though Australians view their natural environment as a

176 core component of their national identity (Purdie \& Wilss, 2007). This suggests Australians

177 could be especially sensitive to economic and national identity loss messages. Further still, the

178 United States has also experienced significant political polarization (Finkel et al., 2020),

179 especially regarding climate change (Dunlap et al., 2016). Therefore, a United States sample also

180 provides the opportunity to potentially replicate and extend upon any potential effects found in

181 Australia.

182 In both studies, we employed a between-subjects experimental research design, with one

183 factor (message type) that had three levels (economic loss, national identity loss, control).

184 Participants were randomly assigned to one of these three message conditions (i.e., levels). As

185 one of our message types threatened national identity (i.e., national identity loss message), we 
CHANGE POLICY SUPPORT

186 also measured and controlled for the potentially confounding impact of national identity in both 187 studies.

\section{Study 1: The Australian Context}

The first study examined the aims outlined above in an Australian sample. We

190 hypothesized that there would be a direct, negative effect of right-wing political orientation on

191 climate change policy support (mitigation, adaptation) (H1). When controlling for Australian

192 identity, those who were politically right-leaning would report lower rates of policy support. We

193 also hypothesized that there would be an interaction effect of message type, in that the message 194 participants received would interact with their political orientation to further contribute to their

195 level of climate change policy support (mitigation, adaptation) (H2). Specifically, when

196 controlling for Australian identity, higher rates of climate policy support would be observed in 197 right-leaning individuals receiving the national identity loss message or economic loss message 198 relative to those who received a control message.

199 Method

Participants and Procedure. A total of 684 Australian citizens/residents were originally 201 recruited via the Australian market research firm PureProfile. Participants who did not complete 202 the full questionnaire $(n=5)$ or who failed at least one of the two attention checks $(n=121)$

203 were removed, leaving a final sample of 558. Participants were aged between 18 and $86\left(M_{\text {age }}=\right.$ $20447.12, S D_{\text {age }}=16.96 ;$ male $=307(55.32 \%)$, female $=247(44.50 \%)$, non-binary $=1(.18 \%)$, 205 missing $=3$ )). Other demographics are in the supplementary materials. 
The market research company PureProfile advertised the study to their participant pool in

207 July $2018^{1}$, actively targeting those who had indicated previously to them that they either self-

208 identified as politically left-leaning $(n=276)$ or politically right-leaning $(n=282)$. To reduce

209 demand characteristics, participants were told that the study assessed their understanding of

210 science communication, with no reference made to climate change in recruitment materials.

211 After reading the plain language statement and providing consent, all participants completed the

212 pre-message measures and then were randomly allocated to receive one of the three messages

213 using the automatic randominsation feature in Qualtrics. Participants then completed the post-

214 message measures. The study was 10 minutes and participants were paid \$AUD5.30 in

215 compensation.

$216 \quad$ Pre-Message Measures.

217 Participants' age, gender, education, income, and state of residence was collected.

218 Participants' strength of Australian identity was measured using a single item ('I identify with

219 Australians', 1 = strongly disagree, = 7 strongly agree) (Postmes, Haslam, \& Jans, 2013). A

220 single-item measure of political orientation was also employed ('In politics people sometimes

221 talk of the left-wing and right-wing. Where would you place yourself? $1=$ very left-wing, $7=$

\footnotetext{
${ }^{1}$ Data collection was completed before the change in Prime Ministership in August 2018, which occurred due to ongoing internal party disagreement in the Liberal/National Coalition regarding climate change and renewable energy policy.
} 
222 very right-wing $)^{2} 3$. The higher one scored on this item, the more they identified as politically 223 right-leaning.

\section{Message Frames.}

Each message was a fictitious online newspaper article which detailed a new report

226 released by leading university scientists. The first message outlined that the national economy

227 would be threatened if effective climate policy was not implemented (economic loss message).

228 The second message outlined how Australia's natural icons would be jeopardized or lost, and

229 therefore Australia's unique cultural identity and way of life, would be under threat if effective

230 climate change policy was not implemented (national identity loss message). The third message

231 served as a control condition and described how antibiotic resistance was predicted to threaten

232 Australia's health outcomes (control message). See supplementary materials for a copy of the

233 message types.

234 Post-Message Measures.

235 Attention and Manipulation Checks

236 Using two items, we checked that participants read and understood their randomly

237 allocated message (Attention check 1: What issue did the newspaper article discuss?; Attention

238 check $2=$ What negative impacts did the newspaper article discuss?). Participants who failed at

\footnotetext{
${ }^{2}$ Left-wing and right-wing were used as anchor points on the scale in Study 1 rather than the typical liberal and conservative anchor points seen in the research literature. This is because within the Australian context the major conservative party is called the Liberal Party, and as such it may have confused Australian participants who are not clear on the distinction between party labelling and ideological labelling.

${ }^{3}$ We also assessed political beliefs with two additional measures of right-wing ideological beliefs for purposes outside the scope of this study. These included Social Dominance Orientation (SDO7) (Ho et al., 2015) and RightWing Authoritarianism (Dunwoody \& Funke, 2016). However, we ran the same analyses with SDO and RWA replacing the single-item measure of political orientation with either SDO or RWA to see whether the findings held. We found the same results reported in this manuscript. Therefore, for the sake of clarity, the descriptives of SDO and RWA and associated analyses are instead reported in the supplementary materials.
} 
CHANGE POLICY SUPPORT

239 least one of these two attention checks were excluded from final analyses $(n=121)$ (see

240 supplementary materials for more details). We also asked participants to indicate the likelihood

241 that climate change would impact the outcome outlined in their allocated message to ensure the

242 manipulations were successful ('How likely is that climate will influence economic prosperity

243 /Australian identity/ /antibiotic effectiveness?') (1 = Not at all, 7 = A great deal). Analyses

244 indicated that the manipulations were effective (see supplementary materials for details and

245 results of these analyses).

$246 \quad$ Climate Change Policy Support

247 Bateman and O'Connor's (2016) two-factor climate change policy support scale

248 measured participants support for mitigation policies (e.g., "implementing a "carbon tax" on coal

249 and other fossil fuels to reduce their use", 6-items) and adaptation policies (e.g., "Setting aside

250 land corridors to help species migrate", 5 -items) $(1=$ strongly disagree, $7=$ strongly agree $)$.

$251 \quad$ Results

252 We used R (Version 4.0.2; R Core Team, 2020) and the R-packages apaTables (Version

253 2.0.5; Stanley, 2018), psych (Version 2.0.12; Revelle, 2018), tableone (Version 0.9.3; Yoshida \&

254 Bohn., 2018), and interactions (Version, 1.1.3; Long, 2020) for our all analyses.

\section{Descriptives.}

Table 1 presents the descriptives for the major continuous variables in Study 1. The

257 sample overall largely identified as Australian and demonstrated moderate to high support for

258 both mitigation and adaptation policy. There was a small, positive correlation between Australian

259 identity and political orientation, suggesting that identifying as an Australian was weakly related

260 to whether one was politically right-leaning. Australian identity had no relationship with

261 mitigation policy support, and a small, positive relationship with adaptation policy support. 
CHANGE POLICY SUPPORT

262 Right-wing political orientation was negatively related to both mitigation and adaptation policy

263 support, and moderately so in the case of mitigation policy.

Table 1

Means, Standard Deviations, Correlations, and Reliability Estimates for Study 1

\begin{tabular}{lccccccc}
\hline Variables & $\boldsymbol{M}$ & $\boldsymbol{S D}$ & $\alpha$ & $\omega$ & $\mathbf{1}$ & $\mathbf{2}$ & $\mathbf{3}$ \\
\hline $\begin{array}{l}\text { 1. Australian } \\
\text { Identity }\end{array}$ & 5.24 & 1.32 & & & & & \\
$\begin{array}{l}\text { 2. Political } \\
\text { Orientation }\end{array}$ & 3.96 & 1.64 & & & $.10^{*}$ &
\end{tabular}

$[.02, .18]$

3. Mitigation

Policy

5.63

1.12

Support

4. Adaptation

Policy

Support

$5.45 \quad 1.05$
.84

.86

$.12 * *$

$-.19 * *$

$.67 * *$

$[.03, .20] \quad[-.27,-.11] \quad[.61, .71]$

Note. $N=558 . M=$ Mean. $S D=$ Standard Deviation. $\alpha=$ Cronbach alpha. $\omega=$ McDonald's

Omega. Values in square brackets indicate the $95 \%$ confidence interval for each correlation. All scales measured on a 1 to 7 scale.

273

274

Despite initial data collection resulting in even participant numbers across the three

message frame conditions $(N=684$, economic loss $n=224$, national identity loss $n=229$,

276 control $n=231$ ), removal of participants who failed attention checks resulted in uneven

277 participant numbers in the three message frame groups $(N=558$, economic loss $n=191$, national

278 identity $\operatorname{loss} n=167$, control $n=200$ ). Therefore, we also conducted two one-way ANOVAs to 
check whether there were any meaningful participant differences on Australian identity and political orientation according to which condition participants were randomly allocated to.

For Australian identity, there was no significant difference between participants who

282 randomly received an economic loss message $(M=5.29, S D=1.21)$, a national identity loss

283 message $(M=5.32, S D=1.42)$, or a control message $(M=5.12, S D=1.33), F(2,555)=1.22, p$

$284=.295$, partial $\eta^{2}=.00$. There was also no significant difference between participants who received 285 an economic loss message $(M=3.89, S D=1.66)$, a national identity loss message $(M=4.01, S D$

$286=1.66)$, or a control message $(M=4.00, S D=1.61)$ on their level of political orientation,

$287 F(2,555)=.28, p=.753$, partial $\eta^{2}=.00$. Therefore, it appeared message randomisation was still

288 successful despite participant numbers differing slightly per condition post data cleaning.

Direct and Interactive Effects on Climate Change Policy Support in Australia.

Two moderated multiple regressions were conducted, one for each dependent variable.

291 We first started by creating two planned orthogonal contrasts to compare the effect the messages

292 frames had on the dependent variables. Firstly, to compare the intervention messages to the

293 control message, we created planned contrast 1, coding: $.5=$ economic loss message, $.5=$

294 national identity message, $-1=$ control message. Then, to compare the intervention messages to

295 one another (while simultaneously controlling for the control message), we created planned

296 contrast $2:-1=$ economic loss message, $1=$ national identity loss message, $0=$ control. To

297 examine the unique effect of the message frames, planned contrasts were entered in at Step 1. In

298 Step 2, we entered the covariates of Australian identity and political orientation. Finally, in Step

299 3, the two-way interactions between political orientation and message type (i.e., contrast 1,

300 contrast 2) were included. A sensitivity power analysis conducted post data collection suggested 
CHANGE POLICY SUPPORT

301 that with a sample of 558, the final sample size would deliver $80 \%$ power to detect an r-square

302 of .025 or greater, with six predictors, at an alpha of .05 .

303 For the outcome variable of mitigation policy support (Table 2), there was no significant

304 effect of message type on mitigation policy support. However, a significant negative effect of

305 political orientation emerged, providing support for H1. When controlling for Australian identity,

306 Australians who were politically right-leaning were less likely to support policies that aim to

307 limit the magnitude or rate of long-term climate change (e.g., emissions trading scheme, carbon

308 tax). However, there was no direct effect of Australian identity. We also obtained no support for

$309 \mathrm{H} 2$; there was no statistically significant political orientation x message type interactions

310 observed on mitigation policy support.

311 For the outcome variable of adaptation policy support (Table 3), there was no significant

312 effect of message type on adaptation policy support, once again suggesting that the message

313 frames did not influence the outcome variable. A significant negative effect of political

314 orientation emerged, providing further support for H1. Australians who were politically right-

315 leaning were less likely to support policies intended to cope with the inevitable effects of climate

316 change, when also controlling for Australian identity. Unexpectedly, we found a significant

317 unique positive effect of Australian identity, in that those who identified more strongly as an

318 Australian were more likely to support adaptation policies. H2 was also not supported as we did

319 not observe any significant political orientation x message type interactions on adaptation policy

320 support. 
CHANGE POLICY SUPPORT

Table 2

Hierarchical Moderated Multiple Regression of Mitigation Policy Support for Study 1

\begin{tabular}{|c|c|c|c|c|c|c|}
\hline & $\beta$ & $\begin{array}{c}\beta \\
95 \% \mathrm{CI}\end{array}$ & $s r^{2}$ & $\begin{array}{c}s r^{2} \\
95 \% \mathrm{CI}\end{array}$ & $R^{2}$ & $\Delta R^{2}$ \\
\hline Step 1 & & & & & $\begin{array}{c}.004 \\
{[.00, .02]}\end{array}$ & \\
\hline Message (interventions vs control) & .08 & {$[-.03, .20]$} & .00 & {$[-.01, .01]$} & & \\
\hline Message (national identity vs economic) & .03 & {$[-.08, .13]$} & .00 & {$[-.00, .00]$} & & \\
\hline Step 2 & & & & & $\begin{array}{c}.142^{* *} \\
{[.09, .19]}\end{array}$ & $\begin{array}{c}.138 * * \\
{[-.08, .19]}\end{array}$ \\
\hline Australian Identity & .05 & {$[-.03, .13]$} & .00 & {$[-.01, .01]$} & & \\
\hline Political Orientation & $-.37 * *$ & {$[-.45,-.30]$} & .14 & {$[.08, .19]$} & & \\
\hline Step 3 & & & & & $\begin{array}{c}.145^{* *} \\
{[.09, .19]}\end{array}$ & $\begin{array}{c}.003 \\
{[-.01, .01]}\end{array}$ \\
\hline $\begin{array}{l}\text { Political Orientation x Message } \\
\text { (interventions vs control) }\end{array}$ & .07 & {$[-.04, .18]$} & .00 & {$[-.01, .01]$} & & \\
\hline $\begin{array}{l}\text { Political Orientation x Message (national } \\
\text { identity vs economic) }\end{array}$ & -.03 & {$[-.12, .07]$} & .00 & {$[-.00, .00]$} & & \\
\hline
\end{tabular}

Note. $N=558 . \beta=$ standardized regression weights. $s r^{2}=$ semi-partial correlation squared. $R^{2}=$ coefficient of determination. $\Delta R^{2}=$ change in $R^{2} .95 \% \mathrm{CI}=95 \%$ confidence interval.

Square brackets enclose the lower and upper limits of a $95 \%$ confidence interval.

$* * p<.01$. 
CHANGE POLICY SUPPORT

Table 3

Hierarchical Moderated Multiple Regression of Adaptation Policy Support for Study 1

\begin{tabular}{|c|c|c|c|c|c|c|}
\hline & $\beta$ & $\begin{array}{c}\beta \\
95 \% \mathrm{CI}\end{array}$ & $s r^{2}$ & $\begin{array}{c}s r^{2} \\
95 \% \mathrm{CI}\end{array}$ & $R^{2}$ & $\Delta R^{2}$ \\
\hline Step 1 & & & & & $\begin{array}{c}.001 \\
{[.00, .01]}\end{array}$ & \\
\hline Message (interventions vs control) & .05 & {$[-.06, .17]$} & .00 & {$[-.00, .01]$} & & \\
\hline Message (national identity vs economic) & .00 & {$[-.10, .11]$} & .00 & {$[-.00, .00]$} & & \\
\hline Step 2 & & & & & $\begin{array}{c}.055^{* *} \\
{[.02, .09]}\end{array}$ & $\begin{array}{c}.053 * * \\
{[.02, .09]}\end{array}$ \\
\hline Australian Identity & $.14 * *$ & {$[.05, .22]$} & .02 & {$[-.00, .04]$} & & \\
\hline Political Orientation & $-.20 * *$ & {$[-.28,-.12]$} & .04 & {$[.01, .07]$} & & \\
\hline Step 3 & & & & & $\begin{array}{c}.055^{* *} \\
{[.02, .09]}\end{array}$ & $\begin{array}{c}.001 \\
{[-.00, .00]}\end{array}$ \\
\hline $\begin{array}{l}\text { Political Orientation x Message } \\
\text { (interventions vs control) }\end{array}$ & .03 & {$[-.08, .15]$} & .00 & {$[-.00, .00]$} & & \\
\hline $\begin{array}{l}\text { Political Orientation x Message (national } \\
\text { identity vs economic) }\end{array}$ & .01 & {$[-.09, .11]$} & .00 & {$[-.00, .00]$} & & \\
\hline
\end{tabular}

Note. $N=558 . \beta=$ standardized regression weights. $s r^{2}=$ semi-partial correlation squared. $R^{2}=$ coefficient of determination. $\Delta R^{2}=$ change in $R^{2} .95 \% \mathrm{CI}=95 \%$ confidence interval.

Square brackets enclose the lower and upper limits of a $95 \%$ confidence interval.

$* * p<.01$. 


\section{Discussion}

Using an Australian sample, Study 1 investigated whether there was a relationship between climate change loss messages (i.e., economic and national identity loss) and policy support, and whether this relationship was moderated by right-wing political orientation. We also measured Australian identity to control for its potential impact on the major variables of the study. As hypothesized, political orientation negatively predicted climate policy support, with those who were politically-right leaning less likely to support mitigation and adaptation policies. Consistent with emerging research, mitigation policies appeared to be more politically divisive in the Australian context (Bateman \& O’Connor, 2016; Tranter \& Lester, 2017), with the negative effect of political orientation stronger in the context of mitigation policies than adaptation policies.

Identifying as Australian was weakly related to political orientation, yet it did predict support for adaptation policy (but not mitigation policy) when controlling for message type and political orientation. Therefore, it appears that national identity may have different implications in the Australian context, such as not being tied strongly to being right-wing as is the case in the United States (Osborne et al., 2017; Roccas et al., 2010). Furthermore, the association between Australian national identity and support for adaptation policy (but not mitigation policy) may be partially explained by how Australians typically view environmental icons as crucial to their national identity (Bonaiuto, Breakwell, \& Cano, 1996; Purdie \& Wilss, 2007). While mitigation policies are focused on reducing the severity of carbon emissions, adaptation policies are typically oriented towards protecting and preserving natural environments via technological advancements, and this could include some of these environmental icons in Australia (e.g., protecting coastal areas like the Great Barrier Reef, protecting against bushfires in iconic areas). 
Nevertheless, neither the economic loss nor national identity loss messages influenced policy support, and the effectiveness of these messages was not conditional on political orientation. Therefore, presenting Australians with messages which emphasize the potential threats to the economy or the potential loss of Australia's environmental icons, relative to a control condition, did not increase climate policy support. This was the case even for adaptation policies and for participants who were more politically right-leaning.

Overall, the mean of Australian identity was high, suggesting most participants largely identified as Australian. As we actively targeted those who had indicated previously that they either self-identified as politically left-leaning $(n=276)$ or politically right-leaning $(n=282)$, our sample also did not skew towards one end of the political spectrum. Furthermore, mitigation and adaptation policy support were reasonably high across all conditions. This suggests that there may have been a potential ceiling effect, in that we did not observe any meaningful differences between groups according to message type because participants on average supported mitigation and adaptation strategies. It is also possible that our sample contained individuals who were skeptical or denied climate change, as these participants were not screened out prior to receiving one of the messages. As noted above, prior research has demonstrated that those who are politically right-leaning in Australia and the United States are more likely to deny the existence of climate change (Clarke et al., 2019; Hornsey et al. 2018), with this political polarization especially strong in the United States (Finkel et al., 2020). Therefore, it can be argued that those who deny climate change and its impacts simply do not think it is an issue worth acting upon and are therefore less likely to attend to and process information which suggests climate policy should be enacted. This may partially explain why although participants understood the content of the national identity and economic loss messages (that is, the manipulations were successful), 
CLIMATE CHANGE COMMUNICATIONS

the messages did not contribute to climate change policy support. Thus, in Study 2, we sought to recruit a United States sample where participants believed climate change was real and that it was happening, testing the same message types and potential interactions in this specific sample.

\section{Study 2: The United States}

In Study 2, we sought to test the same aims from Study 1, but this time in a sample from the United States who believed climate change is human-induced and occurring. We had the same hypotheses for Study 2 as those in Study 1, except this time we controlled for American identification.

\section{Method}

Participants and Procedure. A total of 1,060 American citizens and/or residents were recruited via Amazon Mechanical Turk (MTurk) using TurkPrime. Participants who did not complete the full questionnaire $(n=44)$, who failed at least one of the attention checks $(n=77)$, and who did not believe in climate change $(n=83)$ were excluded. This resulted in a final sample of 859 , with participants aged between 18 and $78\left(M_{\text {age }}=40.00, S D_{\text {age }}=12.25 ;\right.$ male $=$ $395(45.99 \%)$, female $=456(53.08 \%)$, non-binary $=7(.81 \%)$, missing $=1)$. Other demographics are in the supplementary materials.

To minimize sampling bias, we actively targeted participants who had indicated previously on TurkPrime that they self-identified as either liberal $(n=460)$ or conservative $(n=$ 399). Data was collected in July 2019, took 10 minutes, and participants were paid \$US1 compensation. The Study 2 procedure was the same as Study 1, except that participants' climate change belief was asked before they randomly received one of the three messages. 


\section{Measures.}

We employed the same measures in Study 2 except for the changes outlined below. Participants' strength of American identity was measured using the single-item measure ('I identify with Americans', 1 = strongly disagree, 7 = strongly agree) (Postmes et al., 2013). A single-item measure of political orientation was employed ('In politics people sometimes talk of liberals and conservatives. Where would you place yourself?', $1=$ very liberal, $7=$ very conservative). The messages contained the same content as Study 1 except that we replaced all Australian information with American relevant information, and manipulation checks indicated that the manipulations were once again effective (see supplementary materials for analyses).

\section{Climate change beliefs}

Belief that climate change is occurring was measured with a categorical item before participants were presented with their randomly allocated message (Greenhill, Leviston, Leonard, \& Walker, 2014). Analyses revealed that believing climate change was occurring (either naturally or human induced) was associated with a significant, positive increase in mitigation and adaptation policy support when compared to those who denied climate change or were unsure it was occurring. Therefore, participants who indicated they did not believe in climate change or were unsure were excluded from the final analyses (excluded $n=83$; more details can be found in the supplementary materials).

\section{Results}

We used the same R packages as in Study 1 to conduct all analyses.

\section{Descriptives.}

Table 4 presents descriptives for the major continuous variables in Study 2. 
Table 4

Means, Standard Deviations, Correlations, and Reliability Estimates for Study 2

\begin{tabular}{|c|c|c|c|c|c|c|c|}
\hline Variables & $M$ & $S D$ & $\alpha$ & $\omega$ & 1 & 2 & 3 \\
\hline $\begin{array}{l}\text { 1. American } \\
\text { Identity }\end{array}$ & 5.32 & 1.35 & & & & & \\
\hline $\begin{array}{l}\text { 2. Political } \\
\text { Orientation }\end{array}$ & 3.78 & 1.98 & & & $\begin{array}{c}.40^{* *} \\
{[.35, .46]}\end{array}$ & & \\
\hline $\begin{array}{l}\text { 3. Mitigation } \\
\text { Policy } \\
\text { Support }\end{array}$ & 5.82 & 1.18 & .91 & .94 & $\begin{array}{c}-.20 * * \\
{[-.26,-.13]}\end{array}$ & $\begin{array}{c}-.53 * * \\
{[-.57,-.48]}\end{array}$ & \\
\hline $\begin{array}{l}\text { 4. Adaptation } \\
\text { Policy } \\
\text { Support }\end{array}$ & 5.59 & 1.12 & .85 & .88 & {$[-.16,-.02]$} & {$[-.42,-.30]$} & {$[.68, .75]$} \\
\hline
\end{tabular}

Note. $N=859 . M=$ Mean. $S D=$ Standard Deviation. $\alpha=$ Cronbach alpha. $\omega=$ McDonald's Omega. Values in square brackets indicate the $95 \%$ confidence interval for each correlation. All scales measured on a 1 to 7 scale.

$* p<.05 . * * p<.01$.

Overall, participants mostly identified as American, and support for both mitigation and adaptation policies were high in the sample. There was a moderate, positive relationship between American identity and political orientation, suggesting that identifying as an American was positively associated with being conservative. While American identity had weak, negative relationships with both policy support types, political orientation had a strong, negative relationship with mitigation policy support, and a moderate, negative relationship with adaptation policy support.

Like in Study 1, removal of participants who failed attention checks resulted in uneven participant numbers in the three message frame groups $(N=859$, economic loss $n=294$, national identity loss $n=278$, control $n=287$ ). Therefore, we also conducted two one-way ANOVAs to 
check whether there were any meaningful participant differences on Australian identity and political orientation according to which condition participants were randomly allocated to.

For American identity, there was no significant difference between participants who received an economic loss message $(M=5.29, S D=1.37)$, a national identity loss message $(M=$ $5.27, S D=1.35)$, or a control message $(M=5.39, S D=1.33), F(2,856)=.69, p=.503$, partial $\eta^{2}=$ .00. There was also no significant difference between participants who received an economic loss message $(M=3.76, S D=1.94)$, a national identity loss message $(M=3.89, S D=1.99)$, or a control message $(M=3.70, S D=2.01)$ on their level of political orientation, $F(2,856)=.67, p$ $=.509$, partial $\eta^{2}=.00$. Therefore, it appeared randomisation was still successful despite participant numbers differing slightly per condition post data cleaning.

\section{Direct and Interactive Effects on Climate Change Policy Support in the U.S.}

We used the same data analytic approach as Study 1, conducting moderated multiple regressions and using planned contrasts to compare the effectiveness of the message types on both dependent variables. We again conducted a sensitivity power analysis post data collection. A final sample size of 859 was found to deliver $80 \%$ power to detect an r-square of .016 or greater, with six predictors, at an alpha of .05 .

For the outcome variable of mitigation policy support (Table 5), there was no significant effect of message type suggesting that the message frames did not influence this type of policy support. However, a significant negative effect of political orientation emerged, once again providing support for H1. Participants who identified as conservative and believed in climate change were less likely to support mitigation policies, when controlling for American identity. There was no direct effect of American identity on mitigation policy support. We also obtained 
no support for $\mathrm{H} 2$; there was no statistically significant political orientation $\mathrm{x}$ message type interactions observed on mitigation policy support.

For the outcome variable of adaptation policy support (Table 6), we did not find a significant direct effect of message frame. However, a significant negative effect of political orientation emerged, providing further support for H1. Americans who identified as conservative and believed in climate change were less likely to support adaptation policies, when controlling for American identity. Unlike Study 1, we did not unexpectedly find a direct effect of American identity on adaptation policy. Contrary to $\mathrm{H} 2$, there were no significant political orientation $\mathrm{x}$ message frame type interactions observed on adaptation policy support. 
Table 5

Hierarchical Moderated Multiple Regression of Mitigation Policy Support for Study 2

\begin{tabular}{|c|c|c|c|c|c|c|}
\hline & $\beta$ & $\begin{array}{c}\beta \\
95 \% \mathrm{CI}\end{array}$ & $s r^{2}$ & $\begin{array}{c}s r^{2} \\
95 \% \mathrm{CI}\end{array}$ & $R^{2}$ & $\Delta R^{2}$ \\
\hline Step 1 & & & & & $\begin{array}{c}.004 \\
{[.00, .02]}\end{array}$ & \\
\hline Message (interventions vs control) & -.07 & {$[-.17, .02]$} & .00 & {$[-.00, .01]$} & & \\
\hline Message (national identity vs economic) & .04 & {$[-.04, .13]$} & .00 & {$[-.00, .01]$} & & \\
\hline Step 2 & & & & & $\begin{array}{c}.281 * * \\
{[.23, .33]}\end{array}$ & $\begin{array}{l}.277 * * \\
{[.23, .33]}\end{array}$ \\
\hline $\begin{array}{l}\text { American Identity } \\
\text { Political Orientation }\end{array}$ & $\begin{array}{c}.02 \\
-.53 * *\end{array}$ & $\begin{array}{l}{[-.04, .08]} \\
{[-.60,-.47]}\end{array}$ & $\begin{array}{l}.00 \\
.24\end{array}$ & $\begin{array}{l}{[-.00, .00]} \\
{[.19, .29]}\end{array}$ & & \\
\hline Step 3 & & & & & $\begin{array}{c}.285 * * \\
{[.23, .33]}\end{array}$ & $\begin{array}{c}.004 \\
{[-.00, .01]}\end{array}$ \\
\hline $\begin{array}{l}\text { Political Orientation x Message } \\
\text { (interventions vs control) }\end{array}$ & -.07 & {$[-.15, .01]$} & .00 & {$[-.00, .01]$} & & \\
\hline $\begin{array}{l}\text { Political Orientation x Message (national } \\
\text { identity vs economic) }\end{array}$ & .04 & {$[-.03, .11]$} & .00 & {$[-.00, .00]$} & & \\
\hline
\end{tabular}

Note. $N=859 . \beta=$ standardized regression weights. $s r^{2}=$ semi-partial correlation squared. $R^{2}=$ coefficient of determination. $\Delta R^{2}=$ change in $R^{2} .95 \% \mathrm{CI}=95 \%$ confidence interval.

Square brackets enclose the lower and upper limits of a $95 \%$ confidence interval.

$* p<.05 . * * p<.01$. 
Table 6

Hierarchical Moderated Multiple Regression of Adaptation Policy Support for Study 2

\begin{tabular}{|c|c|c|c|c|c|c|}
\hline & $\beta$ & $\begin{array}{c}\beta \\
95 \% \mathrm{CI}\end{array}$ & $s r^{2}$ & $\begin{array}{c}s r^{2} \\
95 \% \mathrm{CI}\end{array}$ & $R^{2}$ & $\Delta R^{2}$ \\
\hline Step 1 & & & & & $\begin{array}{c}.005 \\
{[.00, .02]}\end{array}$ & \\
\hline Message (interventions vs control) & -.08 & {$[-.17, .02]$} & .00 & {$[-.00, .01]$} & & \\
\hline Message (national identity vs economic) & .05 & {$[-.03, .13]$} & .00 & {$[-.00, .01]$} & & \\
\hline Step 2 & & & & & $\begin{array}{l}.139 * * \\
{[.10, .18]}\end{array}$ & $\begin{array}{c}.134 * * \\
{[.09, .18]}\end{array}$ \\
\hline American Identity & .07 & {$[-.00, .13]$} & .00 & {$[-.00, .01]$} & & \\
\hline Political Orientation & $-.39 * *$ & {$[-.46,-.32]$} & .13 & {$[.08, .17]$} & & \\
\hline Step 3 & & & & & $\begin{array}{c}.140 * * \\
{[.09, .18]}\end{array}$ & $\begin{array}{c}.001 \\
{[-.00, .00]}\end{array}$ \\
\hline $\begin{array}{l}\text { Political Orientation x Message } \\
\text { (interventions vs control) }\end{array}$ & -.00 & {$[-.09, .08]$} & .00 & {$[-.00, .00]$} & & \\
\hline $\begin{array}{l}\text { Political Orientation x Message (national } \\
\text { identity vs economic) }\end{array}$ & .03 & {$[-.05, .11]$} & .00 & {$[-.00, .00]$} & & \\
\hline
\end{tabular}

Note. $N=859 . \beta=$ standardized regression weights. $s r^{2}=$ semi-partial correlation squared. $R^{2}=$ coefficient of determination. $\Delta R^{2}=$ change in $R^{2} .95 \% \mathrm{CI}=95 \%$ confidence interval.

Square brackets enclose the lower and upper limits of a $95 \%$ confidence interval.

$* p<.05 . * * p<.01$. 


\section{Discussion}

In Study 2, we collected a sample of United States citizens and/or residents who believed climate change was occurring to investigate the relationship between climate change loss messages and policy support, and to test whether this relationship was moderated by conservative political orientation. We also controlled for American identity. As hypothesized and consistent with Study 1, conservatives were less likely to support mitigation and adaptation policies, and this negative direct effect was stronger in the context of mitigation policies than adaptation policies (Bateman \& O’Connor, 2016). However, unlike in Study 1, there was no direct effect of American identity on support for adaptation policies. Therefore, those identifying as an American were not more likely to support adaptation policies. We also found no significant political orientation $\mathrm{x}$ message type interaction on mitigation or adaptation policy support. However, it must be noted that mitigation and adaptation policy support was once again high across all message conditions (as seen in Study 1). Given we only obtained participants who believed in climate change in Study 2, thereby accounting for the impact that climate change deniers may have had in Study 1, it is possible that some potential differences were reduced or not observed in this study due to ceiling effects.

\section{General Discussion}

The aims of this present research were twofold. Our first aim was to investigate whether an economic loss or national identity loss message increased climate policy support (mitigation, adaptation) when compared to one another and to a control message in Australia (Study 1) and the United States (Study 2). Secondly, as right-wing adherents are less likely to support climate change policy in these countries, but national identity is typically related to conservatism, we also aimed to test whether the effectiveness of these climate messages was conditional on 
identifying as politically right-leaning (Study 1 in Australia) or conservative (Study 2 in the U.S.). As one of our message types threatened national identity (i.e., national identity loss message), we also measured participants' level of national identification to control for its potential effect on the variables of the study.

Across the two studies, we found a direct, negative effect of political orientation on climate change policy support. When controlling for Australian (Study 1) or American (Study 2) identity, right-wing adherents were less likely to support mitigation and adaptation policies. This is consistent with previous research that has shown that those who are politically left-leaning in Australia and the United States are more likely to support climate change policies and action when compared to their right-wing counterparts (Fielding et al., 2012; Hornsey et al., 2018; Dunlap et al., 2016; Unsworth \& Fielding, 2014). Interestingly, this negative relationship was more pronounced with mitigation policy support in both Australia (Study 1) and the United States (Study 2), suggesting that conservative respondents were less hostile to adaptation policies than mitigation policies. Mitigation policies are focused on limiting the severity of climate change, primarily through reducing carbon emissions via governmental policy. Therefore conservatives may either be less concerned about the severity of climate change, believe reducing carbon emissions is a less appropriate course of climate action, or more resistant to governmental policies which rely on changes to the current socio-economic or tax system (e.g., the carbon tax). This may be due to the varying level of socio-economic change mitigation and adaptation strategies require. Mitigation policies typically involve substantial changes, and therefore threats, to the current socio-economic and cultural system as they aim to limit the existing impacts of climate change through governmental intervention, which right-wing adherents are particularly sensitive and reactive to (Clarke et al., 2019; Feygina et al., 2012). 
Adaptation policies, on the other hand, are strategies which typically fit into the current socioeconomic and cultural system and do not require an acceptance that the impact of climate change is severe. Furthermore, although adaptation policies are driven by governments, they require less systemic change and so may therefore be seen as less threatening to right-wing adherents. Future research should investigate the varying reactions to mitigation and adaptation policies, and whether these are conditional on political orientation, to fully understand these potential differences.

In terms of the effectiveness of loss messages (economic, national identity) when compared to one another and to a control message, findings from both studies showed that support for climate policy was not influenced by message loss type, and that there was no conditional effect of political orientation on responses to these messages. This suggests that attempting to generate communications that emphasize loss and that align with conservative economic (economic growth) or cultural (nationalism) values may be unable to reduce politicization of climate change in Australia (Study 1) and the U.S. (Study 2). While this finding was unexpected, it is unlikely due to issues with our manipulations or that participants were unable to distinguish between the economic or national impacts of climate change. Participants who had received a national identity loss message perceived that climate change would impact the Australian (Study 1) or American (Study 2) way of life when compared to those who received the economic message (and vice versa) (see supplementary materials for these analyses). These findings contrast with prior research which shows pro-environmental, patriotic messages are well received by conservatives (Feygina et al., 2010; Wolsko et al., 2016) and those right-wing adherents are open to protecting the environment if it also means protecting national interests (McCright \& Dunlap, 2014). Nonetheless, the findings do align with emerging 
research that demonstrates that messages that attempt to align with conservative beliefs do no reduce political polarization of climate change (Chinn \& Hart, 2021) or can even lead to some form of reactance, with right-wing adherents viewing climate change policy as less important post-message (Singh \& Swanson, 2017). It is also important to note that the source of our message were university scientists, and while generally trusted, these may not be trusted by right-wing adherents when it comes to climate change. While not the same source employed in our study, recent research has demonstrated left-leaning sources result in more positive attitudes towards climate policies for left-wing adherents, yet this does not occur when right-leaning sources present the same information to right-wing adherents (Fielding et al., 2020). Therefore, future research should further investigate whether loss messages that tap into traditional conservative economic (economic growth) or cultural (nationalism) values may work in specific countries, with policy types, and with certain sources (e.g., political in-group members).

An unexpected finding of the current research was that we found a positive, unique effect of participant national identity on support for adaptation policy in our Australian sample (Study 1). While this effect was smaller than political orientation in both studies, those who more strongly identified as Australian were more likely to support adaptation policies, but not mitigation policies. Firstly, this suggests that it is still possible to utilize national identity as a potential driver of adaptation policy support, especially in Australia, which is less politically polarized than the United States (Finkel et al., 2020). This is because while prior research shows that nationalism is positively related to right-wing ideologies in the United States (Roccas et al., 2010), there was only a weak, positive relationship between Australian identity and right-wing orientation in our research. Further still, prior research suggests that Australians do view 'caring for the environment' as an important part of their national identity (Purdie \& Wilss, 2007). 
Secondly, this unexpected finding suggests that adaptation policies, which are focused on adapting to the negative environmental effects of climate change, may have different psychological antecedents to those policies which are focused on limiting the severity of climate change. As noted above, mitigation policies tend to result in system change (Clarke et al., 2019), while adaptation policies typically result in changes within an existing system. Therefore, it is possible that those who strongly identify with their national social group find small changes in a system they already value (i.e., their country) more palatable. Future research should explore the utility of national identity as an antecedent to adaptation policy support and see whether it could be more effectively employed in climate change communication, especially in Australia.

\section{Limitations}

The current research provided an experimental test of whether economic loss or national loss messages may contribute to climate change policy support across two different countries Australia (Study 1) and the United States (Study 2). While political orientation does contribute to climate change outcomes in these countries, it is possible that different effects may arise in other countries where climate change is not politically polarizing (Smith \& Mayer, 2019).

Furthermore, the findings across the two studies did differ somewhat, suggesting potential country-level differences in how individuals respond to climate change communications. Although prior research demonstrated that national identity is related to political conservatism in Anglosphere nations, we did not find this in the Australian context in Study 1 (there was only a weak relationship), and so its ability to accentuate the impact of political conservatism may have been weaker than in the U.S. context. Finally, while there was appreciable variability within conditions, the average endorsement of policies was reasonably high across all groups in both studies. As such, this may limit inference to those strongly opposed to adaptation and mitigation 
strategies and may further have put a limit on the size of the observable effects due to measurement ceilings.

\section{Conclusion}

Across two studies, and in line with prior research, we found that identifying as politically right-leaning (in Australia, Study 1) or conservative (in the United States, Study 2) was negatively related to both mitigation and adaptation policy support, providing further evidence that governmental climate action is politically polarized in these nations. Yet, we also found that Australian (Study 1) identity was uniquely and positively predictive of adaptation policy support, but not mitigation policy support. This suggests that different psychological variables may predict different types of climate policies, and in the case of this research, those who identify as an Australian appear more likely to support policies which simply adhere to the current political environment rather than change the socio-economic and cultural system. Findings across the two studies also showed that an economic loss and national identity loss message did not result higher mitigation and adaptation policy support when compared to one another or to a control, and this was not conditional on right-wing political attitudes. These findings suggest that if one must discuss climate change, describing the threat to cultural symbols and national environmental icons, or the potential economic losses if we do not act on climate change, may do little to increase climate policy support in right-wing adherents. 


\section{References}

Bain, P. G., Milfont, T. L., Kashima, Y., Bilewicz, M., Doron, G., Garoarsdóttir, R. B., . . Saviolidis, N. M. (2016). Co-benefits of addressing climate change can motivate action around the world. Nature Climate Change, 6(2), 154-157. doi:10.1038/nclimate2814

Bateman, T. S., \& O’Connor, K. (2016). Felt responsibility and climate engagement: Distinguishing adaptation from mitigation. Global Environmental Change, 41, 206-215. doi.org/10.1016/j.gloenvcha.2016.11.001

Bertolotti, M., \& Catellani, P. (2021). Going Green, but Staying in the Black: How Framing Impacts the Agreement With Messages on the Economic Consequences of Environmental Policies. Frontiers in Psychology, 12(1192). doi:10.3389/fpsyg.2021.624001

Bertolotti, M., Catellani, P., \& Nelson, T. (2021). Framing Messages on the Economic Impact of Climate Change Policies: Effects on Climate Believers and Climate Skeptics. Environmental Communication, 15(6), 715-730. doi:10.1080/17524032.2021.1890175

Bonaiuto, M., Carrus, G., Martorella, H., \& Bonnes, M. (2002). Local identity processes and environmental attitudes in land use changes: The case of natural protected areas. Journal of Economic Psychology, 23(5), 631-653. doi:10.1016/S0167-4870(02)00121-6

Chinn, S., \& Hart, P. S. (2021). Effects of consensus messages and political ideology on climate change attitudes: inconsistent findings and the effect of a pretest. Climatic Change, 167(3), 47. doi:10.1007/s10584-021-03200-2

Clarke, E. J. R., Ling, M., Kothe, E. J., Klas, A., \& Richardson, B. (2019). Mitigation system threat partially mediates the effects of right-wing ideologies on climate change beliefs. Journal of Applied Social Psychology, 49(6), 349-360. doi:10.1111/jasp.12585 
Clayton, S., Devine-Wright, P., Swim, J., Bonnes, M., Steg, L., Whitmarsh, L., \& Carrico, A. (2016). Expanding the role for psychology in addressing environmental challenges. American Psychologist, 71(3), 199-215. doi:10.1037/a0039482

Department of the Environment and Energy. (2018). Climate change impacts in Australia. Retrieved from http://www.environment.gov.au/climate-change/climate-science$\underline{\text { data/climate-science/impacts }}$

Dunlap, R. E., McCright, A. M., \& Yarosh, J. H. (2016). The Political Divide on Climate Change: Partisan Polarization Widens in the U.S. Environment: Science and Policy for Sustainable Development, 58(5), 4-23. doi:10.1080/00139157.2016.1208995

Feygina, I., Jost, J. T., \& Goldsmith, R. E. (2010). System justification, the denial of global warming, and the possibility of "system-sanctioned change". Personality and Social Psychology Bulletin, 36(3), 326-338. doi:10.1177/0146167209351435

Fielding, K. S., Head, B. W., Laffan, W., Western, M., \& Hoegh-Guldberg, O. (2012). Australian politicians' beliefs about climate change: political partisanship and political ideology. Environmental Politics, 21(5), 712-733. doi:10.1080/09644016.2012.698887

Fielding, K. S., Hornsey, M. J., Thai, H. A., \& Toh, L. L. (2020). Using ingroup messengers and ingroup values to promote climate change policy. Climatic Change, 158(2), 181199. doi:10.1007/s10584-019-02561-z

Finkel, E. J., Bail, C. A., Cikara, M., Ditto, P. H., Iyengar, S., Klar, S., . . Druckman, J. N. (2020). Political sectarianism in America. Science, 370(6516), 533-536. doi:10.1126/science.abe1715 
Greenhill, M., Leviston, Z., Leonard, R., \& Walker, I. (2014). Assessing climate change beliefs: Response effects of question wording and response alternatives. Public Understanding of Science, 23(8), 947-965. doi:10.1177/0963662513480117

Hart, P. S., \& Nisbet, E. C. (2012). Boomerang Effects in Science Communication:How Motivated Reasoning and Identity Cues Amplify Opinion Polarization About Climate Mitigation Policies. Communication Research, 39(6), 701-723. doi:10.1177/0093650211416646

Hennes, E. P., Ruisch, B. C., Feygina, I., Monteiro, C. A., \& Jost, J. T. (2016). Motivated recall in the service of the economic system: The case of anthropogenic climate change. Journal of Experimental Psychology: General, 145(6), 755-771. https://doi.org/10.1037/xge0000148

Hornsey, M. J., Harris, E. A., \& Fielding, K. S. (2018). Relationships among conspiratorial beliefs, conservatism and climate scepticism across nations. Nature Climate Change, 8(7), 614-620. doi:10.1038/s41558-018-0157-2

Long, J. A. (2020), tableone: interactions: Comprehensive, User-Friendly Toolkit for Probing Interactions (Version 1.1.3) [Computer software]. https://cran.rproject.org/web/packages/interactions/index.html

Jost, J. T., Glaser, J., Kruglanski, A. W., \& Sulloway, F. J. (2003). Political conservatism as motivated social cognition. Psychological bulletin, 129(3), 339. https://doi.org/10.1037/00332909.129.3.339

Klas, A., \& Clarke, E. J. R. (2020). The role of psychological variables in developing effective climate change message frames. In D. C. Holmes \& L. M. Richardson (Eds.), Research Handbook on Communicating Climate Change (pp. 95-105). Cheltenham, UK: Edward Elgar Publishing. 
Koleva, S. P., Graham, J., Iyer, R., Ditto, P. H., \& Haidt, J. (2012). Tracing the threads: How five moral concerns (especially Purity) help explain culture war attitudes. Journal of Research in Personality, 46(2), 184-194. doi:https://doi.org/10.1016/j.jrp.2012.01.006

Leviston, Z., \& Walker, I. (2012). Beliefs and Denials About Climate Change: An Australian Perspective. Ecopsychology, 4(4), 277-285. doi:10.1089/eco.2012.0051

McCright, A. M., \& Dunlap, R. E. (2014). Defeating Kyoto: The Conservative Movement's Impact on U.S. Climate Change Policy. Social Problems, 50(3), 348-373. doi:10.1525/sp.2003.50.3.348

Nisbet, M. C. (2009). Communicating climate change: why frames matter to public engagement. Environment, 51. doi:10.3200/envt.51.2.12-23

Osborne, D., Milojev, P., \& Sibley, C. G. (2017). Authoritarianism and National Identity: Examining the Longitudinal Effects of SDO and RWA on Nationalism and Patriotism. Personality and Social Psychology Bulletin, 43(8), 1086-1099. doi:10.1177/0146167217704196

Postmes, T., Haslam, S. A., \& Jans, L. (2013). A single-item measure of social identification: Reliability, validity, and utility. British Journal of Social Psychology, 52(4), 597617. doi:10.1111/bjso.12006

Purdie, N., \& Wilss, L. (2007). Australian National Identity: Young Peoples’ Conceptions of What It Means to be Australian. National Identities, 9(1), 67-82. doi:10.1080/14608940601145695

Revelle, W. (2020). psych: Procedures for Psychological, Psychometric, and Personality Research (Version 2.0.12) [Computer software]. https://cran.rproject.org/web/packages/psych/index.html 
Roccas, S., Schwartz, S. H., \& Amit, A. (2010). Personal Value Priorities and National Identification. Political Psychology, 31(3), 393-419. doi:10.1111/j.1467-9221.2010.00763.x

Sachs, J., Schmidt-Traub, G., Kroll, C., Lafortune, G., \& Fuller, G. (2021). Sustainable Development Report 2020: The Sustainable Development Goals and Covid-19 Includes the SDG Index and Dashboards (1st ed.). Cambridge University Press. https://doi.org/10.1017/9781108992411

Sapiains, R., Beeton, R. J. S., \& Walker, I. A. (2016). Individual responses to climate change: Framing effects on pro-environmental behaviors. Journal of Applied Social Psychology, 46(8), 483-493. doi:10.1111/jasp.12378

Severson, A. W., \& Coleman, E. A. (2015). Moral frames and climate change policy attitudes. Social Science Quarterly, 96(5), 1277-1290.

Singh, S. P., \& Swanson, M. (2017). How issue frames shape beliefs about the importance of climate change policy across ideological and partisan groups. PLoS ONE, 12(7), 1-14. doi:10.1371/journal.pone.0181401

Stanley, D. (2018). apaTables: Create American Psychological Association (APA) Style Tables. (Version 2.0.5) [Computer software]. https://CRAN.R-project.org/package=apaTables

Steg, L., \& Vlek, C. (2009). Encouraging pro-environmental behaviour: An integrative review and research agenda. Journal of Environmental Psychology, 29(3), 309-317. doi:http://dx.doi.org/10.1016/j.jenvp.2008.10.004

Smith, E. K., \& Mayer, A. (2019). Anomalous Anglophones? Contours of free market ideology, political polarization, and climate change attitudes in English-speaking countries, Western European and post-Communist states. Climatic Change, 152(1), 17-34. doi:10.1007/s10584-018-2332-x 
Tranter, B., \& Lester, L. (2017). Climate patriots? Concern over climate change and other environmental issues in Australia. Public Understanding of Science, 26(6), 738-752. doi:10.1177/0963662515618553

Unsworth, K. L., \& Fielding, K. S. (2014). It's political: How the salience of one's political identity changes climate change beliefs and policy support. Global Environmental Change, 27, 131-137. doi:https://doi.org/10.1016/j.gloenvcha.2014.05.002

Wolsko, C., Ariceaga, H., \& Seiden, J. (2016). Red, white, and blue enough to be green: Effects of moral framing on climate change attitudes and conservation behaviors. Journal of Experimental Social Psychology, 65, 7-19. doi:10.1016/j.jesp.2016.02.005

Yoshida, K., \& Bohn, J. (2018). tableone: Create 'Table 1' to Describe Baseline Characteristics (Version 0.9.3) [Computer software]. https://CRAN.Rproject.org/package=tableone 


\section{Statements and Declarations}

\section{Funding}

This research was supported in part by Deakin University School of Psychology internal Research Funds.

\section{Competing Interests}

The authors declare no competing interests.

\section{Author Contributions}

All authors contributed to conceptualisation and writing the manuscript. AK analysed the data.

\section{Data Availability}

The datasets generated during and/or analysed during the current study are not publicly available as the conditions of ethical approval does not allow for this. However, they are available from the corresponding author on reasonable request. 


\section{Supplementary Files}

This is a list of supplementary files associated with this preprint. Click to download.

- EcoandNatFramesPICCmessagetypes.pdf

- NatldentFramePICCsuppmaterials.pdf 